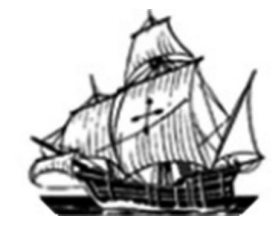

Nau Literária: crítica e teoria de literaturas • seer.ufrgs.br/NauLiteraria ISSN 1981-4526 • PPG-LET-UFRGS • Porto Alegre • vol. 09, n. $01 \bullet$ jan/jun 2013

Dossiê: Literatura Infantil e Alteridade no Mundo Lusófono

\title{
Um menino com a boca suja de poesia
}

\author{
Andrea Cristina Muraro
}

Resumo: Alguns apontamentos sobre a obra Há prendisajens com o xão, do angolano Ondjaki, no que diz respeito aos aspectos temáticos e estilísticos desse livro de poesia, a saber: imbricamento de gêneros, memória e infância, intertextualidade e oralidade.

Palavras-chave: Ondjaki; literatura angolana; memória; intertextualidade; oralidade.

\begin{abstract}
Some notes about the work Há prendisajens com o xão, by Ondjaki, with regard to thematic and stylistic aspects of his poetry, namely: overlapping of genres, childhood and memory, intertextuality and orality.
\end{abstract}

Keywords: Ondjaki; Angolan literature; memória; intertextuality; orality.

Quando se pensa no projeto artístico do escritor angolano Ondjaki (1977), como um todo, vemos que Há prendisajens com o xão funciona como uma matriz geradora de temas e procedimentos estéticos. Talvez, por isso, esta obra editada no Brasil em 2011, e publicada anteriormente em 2002 em Angola e Portugal, provoque um estranhamento ao leitor de sua prosa, pois como o próprio autor já comentou em algumas de suas entrevistas (MURARO, 2006, p. 103), parece um projeto inacabado. E o é, já que, contém, a nosso ver, elementos que constantemente se refazem. É nisto que reside a importância de sua publicação no 
Brasil, para o contexto angolano e das literaturas africanas de língua portuguesa: um projeto em constante interação cujo principal mérito é a humanização.

A recombinação de determinados aspectos linguísticos, bem como a mistura de gêneros - conto, carta (p. 30, 68) ao longo da obra, acaba por conferir força poética para a escritura, dando novos matizes e incorporando as articulações semânticas feitas por meio da metáfora chão, que percorre Há prendisajens com o $x \tilde{a} o$ desde o seu título.

Para o leitor da literatura angolana, não se trata, porém, da poesia de combate das décadas anteriores. E apesar dos contornos metapoéticos também se realizarem em Há prendisajens como xão,a idéia da dinamização identitária se manifesta, mais fortemente, pelo diálogo com a terra e seus desdobramentos. Um trecho do prefácio esclarece melhor sobre esta poesia e suas ressonâncias: aprendizagem é a palavra que, ela sim, ramifica e desramifica uma pessoa; ela enlaça, abraça; mastiga um alguém, cuspindo-o a si mesmo, tudo para novas gêneses pessoais. (p.7)

Assim, pode-se pensar que a construção da identidade literária de Ondjaki, vista de dentro do contexto angolano que o precedeu, dá-se não pela necessidade de manter-se fiel ao código até então utilizado, mas em buscar comunicação com uma rede cultural ampla, sem deixar de colocar-se como sujeito de voz própria: marcações perceptíveis na forma como a palavra corporifica seu sentido fônicosemântico, organizado e grafado hibridamente, como o próprio título da obra já sinaliza.

Dessa maneira, os poemas e os paratextos de Há prendisajens com o $x$ ãoramificam-se como organismos alternados entre acentos e temas angolanos, obrigando o código a transformar-se, escapando de um processo ideológico de dominação e mostrando a diferença em termos de valor estético. Para o poeta, esse posicionamento parece se transformar em um método de atravessar os outros, em 
uma aprendizagem (prendisajens) do ser xão em processo, como denuncia o título da obra.

Embora não venha a ser seu viés principal, cabe advertir que uma leitura, que vai além do código verbal, é necessária para Há prendisajenscom o xão,devido à forma gráfica com que os poemas são impressos: todos os versos começam em minúsculas como pequenas raízes fincadas à margem esquerda das folhas, em uma sugestão de plantas-verso crescendo no chão das folhas-livro. Diante dessa interação, onde os códigos se comunicam e se explicam mutuamente, exige-se do leitor um olhar atento,pois os gêneros distribuídos pela obra forçam-nos ao movimento de ir e vir pelas páginas,criam imagens, espaços,cruzamento entre linguagens, de modo que o livro-objeto também é uma de suas dimensões. Os recursos gráficos que o compõem resistem à compreensão imediata, ficamos entre a estranheza provocada pela grafia das palavras, sua voz no sentido valèryano e o pensamento; somos provocados a continuar buscando qual é a fonte dos sentidos,oscilando entre o valor da palavra escrita como variante oral e os sentidos que podem estar presentes nos vocábulos xão e prendisajens.

A poesia de Ondjaki, além de prender-se aos elementos naturais como se vê também no subtítulo (O segredo húmido da lesma \& outras descoisas), apresenta uma forte relação com aquilo é mínimo, minúsculo através do que nos é explicitado pelo jogo de prefixos e sufixos. Cria-se, assim, um círculo sonoro que evoca o contato entre o chão/ xão para espalhar-se pelo campo semântico de, praticamente, todos os poemas da obra, trapaceando no sentido barthesiano da língua.

Por isso, Há prendisajens com o xão vincula-se à vivência afetiva, e como foi dito anteriormente, à humanização, a um saber-sentir territorializado cuja inscrição se faz com barro, areios, grãos, em uma semântica de fertilização, como no poema de abertura: 


\section{CHÃO}

palavras para manoel de barros

apetece-me des-ser-me;

reatribuir-me a átomo.

cuspir castanhos grãos

mas gargantadentro;

isto seja: engolir-me para mim

poucochinho a cada vez

um por mais um: areios.

assim esculpir-me a barro

e re-ser chão. Muito chão.

apetece-me chãonhe-ser-me.(p.11)

Metamorfoseado em chão, ao trocar as máscaras, o eu parece criar uma intricada série de relações entre o título e a composição dos versos, mantendo-nos atentos à construção física do poema ao engolir os grãos cor de terra que vai constituir o próprio ser, a areia que compõe o barro e que volta para o chão são formas de conhecer, de aprendizagem, moldando-se em uma espécie de esculpir interminável. Simultaneamente, temos uma movência de sentidos da metáfora chão que por analogia esbarra no sobrenome do poeta brasileiro, citado na dedicatória barros-, como se ao provar deste barro passasse a ser parte dele, a pertencer a algum chão, no algures do pensamento poético. Ou seja, identifica-se ao conhecer, incluindo-se em uma rede mais ampla da língua portuguesa, atravessando as sintaxes tortas presentes nas obras do poeta brasileiro.

A construção do chão poético em diálogo com elementos da natureza, de forma a caracterizar a fundação desse eu-poético, por meio da própria aprendizagem do fazer poesia, revela um certo tom didático, que, muitas vezes pelos títulos de seus poemas, tais como - Quando fui chão para lágrimaterrizagem e Para pisar um chão de estrelas - Borboletabirinto, ou as definições em versos finais dos poemas - polvo é um sinaleiro em batota, linha de água é espelho, o homem é catinga da natureza, pirilampo é lanterna do poeta - , e também a forma 
como as perguntas são feitas dentro dos poemas; entretanto, o que aprende com os exercícios de linguagem, o eu procura, também, ensinar outras formas de ler poesia, como acontece com os verbetes ao final do livro. Ou ainda no resgate/renovação das formas tradicionais da narração:

\section{ESTÓRIA PARA WANDY}

quero dizer-lhe: muitos mais velhos começam assim uma estória: "era uma vez...", nós começaremos em mais crença: é uma vez uma menina que sabia uma estória: essa estória não era verdadeira, mas de tanto acreditar nela, a coisa se revoltou para averdades, era uma estória muito simples: (p.29)

Em alguns dos contos-poema da obra, existe outra constante temática no projeto literário do autor: a infância. Vale ressaltar do fragmento anterior a temporalidade escolhida pelo "é uma vez", cujo fator de alteridade alerta para a noção de crença, uma espécie de fé no ato de narrar, onde as fronteiras entre ficção e realidade desabam diante da simplicidade e da perspicácia lírica. Não é o caso de discutir o enquadramento da obra como literatura infantil ou não, trata-se de observar que o projeto, no seu todo, busca uma (im)possível memória do presente; nesse sentido, o lirismo consegue atender a essa expectativa de renovação.

Outro aspecto a se acrescentar é o trânsito fluido das palavras do eu e dos outros. A dialética do aprender e do prender-se ( e por que não também desprenderse) estabelece em inúmeras ressonâncias, seja com crianças, bichos ou com outros chãos: os de Manoel de Barros, Clarice Lispector, Borges, Ana Paula Tavares, os do caboverdiano Carlos Barbosa, o da dramaturgia de Ionesco... já que ao buscar alteridade, o poeta evoca escritores e obras bastante representativos desse abocanhar da linguagem poética: despalavreação: é um ensinamento uma desaprendi-zagem. um desmomento. e tem outros nomes: guimarães prosa, 
manoel de barro, luuandino vieira, mia couto, ou qualquer ser humano que sorria no gigantesco significado das coisas insignificantes. (p. 64)

A brincadeira desse verbete remete-nos às edições de obras de língua portuguesa de África, as quais, quando editadas no exterior, carregam um glossário explicativo de seus termos. Intencional ou não, demonstra um agrupamento de autores significativos por seus processos de manipulação inventoada da palavra e sistematizá-los em um glossário nos parece um recurso que inscreve a língua cotidiana ao discurso literário. Os trocadilhos, com os nomes do moçambicano Mia Couto e do mineiro João Guimarães Rosa, ajudam a compor este cenário de aprendizagem com a língua poética de outros prosadores, que se intertextualiza e aponta para o outro-chão da língua, suas maleabilidades, suas várias formas do registro, dialogando com a tradição literária dentro de seu próprio campo comunicativo. Neste caso, o verbete revela a transgressão do discurso literário em relação ao já dicionarizado, pois cria uma nação literária que se reúne em torno da despalavreação, isto é, uma ficcionalização que desautomatiza do uso cotidiano da língua.

Para concluir, vale lembrar que, nesta obra, o poeta tal qual homo ludens, revela as tensões entre o popular o erudito, entre o próprio e o alheio em um mesmo palco, tão bem apresentados em alguns de seus versos finais: chãotoria: quando encostando ouvido no chão, que é dizer, quando emprestando ouvido para chão, assim ouve-se uma ópera-de-chão, à qual também se chama chãotoria. (p. 65)

\section{Referências}

BARTHES, R. O prazer do texto. São Paulo: Perspectiva, 1973. 
HUIZINGA, Johan. Homo Ludens. São Paulo: Perspectiva, 1980.

MURARO, A.C. As prendisajens poéticas em Ondjaki: dimensões da metáfora xão. Dissertação de mestrado. PUC/SP. São Paulo, 2006.

ONDJAKI. Há prendisajens com o xão. Rio de Janeiro: Pallas, 2011.

VALÉRY, Paul. Variedades. São Paulo: Iluminuras, 1999. 